\title{
Auf die Pole-Position
}

Liebe Leserin, lieber Leser,

ein Zitat von Bundesverkehrsminister Andreas Scheuer geht nassforsch in die Vollen: „Deutschland wird international die Nummer 1 beim autonomen Fahren. Als erstes Land weltweit holen wir autonome Fahrzeuge aus den Forschungslaboren auf die Straße - und zwar im Regelbetrieb. (...)." Es folge nun der nächste Schritt mit dem Gesetz zum autonomen Fahren, das einen Rechtsrahmen schaffe, um autonome Kraftfahrzeuge (Stufe 4) [gemeint sind insofern wohl automatisierte Kfz, Anm. d. Red.] in festgelegten Betriebsbereichen im öffentlichen Straßenverkehr im Regelbetrieb fahren zu können. Start dieses Regelbetriebs könnte demnach 2022 sein.

Für die Umsetzung sorgen soll die Automobilindustrie, die dafür ihre (ohnehin großen Anstrengungen) im Bereich automatisiertes Fahren intensivieren solle. Dabei zu beobachten sind momentan zwei konkurrierende Herangehensweisen: eher evolutionär über den stetigen Ausbau der vorhandenen Assistenzsysteme sowie eher revolutionär durch Roboterfahrzeugflotten mit Sicherheitsfahrer, um die Zwischenstufen SAE $2+$ bis 4 möglichst schnell komplett zu überspringen. Letzteres ergibt Sinn, um keine Entwicklungsaltlasten unter der Haube stecken zu haben; allerdings ist der Sprung sehr groß. Zudem ist dies riskant, da es Umfragen gibt, nach denen momentan ein hoher Prozentsatz an Menschen einem autonom fahrenden Fahrzeug nicht vertrauen würde.

Wie wir uns dem SAE-Level 5 annähern und ob Evolution oder Revolution die Nase vorn haben, wird spannend. Tesla als Evolutionsvertreter beispielsweise war Ende 2020 mit Ankündigungen einer neuen Version seines Full Self-Driving in sozialen Medien präsent; das System sei nahe am SAE-Level 5, so Elon Musk. In diesem Zusammenhang ist es allerdings interessant zu lesen, dass Waymo-CEO John Krafcik als Vertreter des revolutionären Ansatzes Tesla - und damit eigentlich auch allen anderen - die Fähigkeit, Level 5 je mit einem evolutionären Ansatz zu erreichen, komplett abspricht. Abgesehen davon, dass einige diese Meinung zu Tesla schon deshalb teilen, weil sie vergleichsweise sparsam Sensorik einsetzen, bleibt die Frage spannend, ob eine Politik der kleinen Schritte wirklich in einem autonomen System resultieren wird.

Wie immer es darum bestellt ist, das deutsche Regelwerk allein reicht nicht. Es sollte eine Vereinheitlichung der Rechtslage für das automatisierte Fahren beziehungsweise dessen Validierung auf europäischer Ebene angestrebt werden. Ein europäisches Rahmenwerk ist essenziell: Wer immer am Ende die Nummer 1 beim automatisierten Fahren sein wird, es könnte ihm leichter gemacht werden, wenn er nicht allzu vielen unterschiedlichen nationalen Regularien folgen muss.

Viel Spaß beim Lesen der Ausgabe!

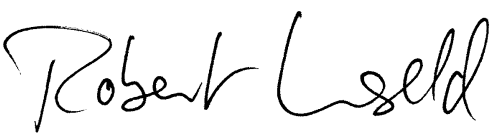

Robert Unseld

Verantwortlicher Redakteur

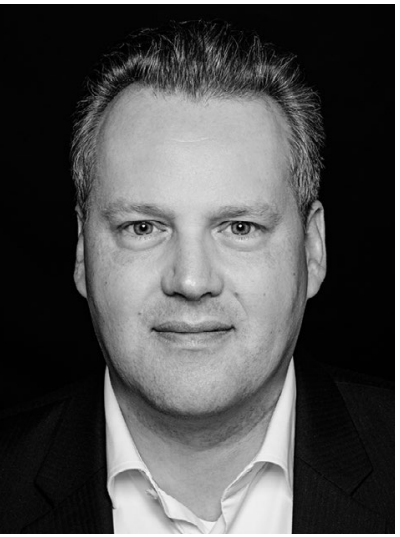

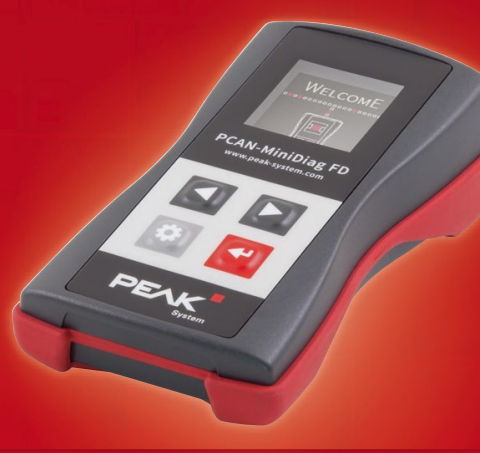

PCAN-MiniDiag FD

Handheld zur grundlegenden Diagnose von CAN- und CANFD-Bussen. Messung der Bitrate, Terminierung, Buslast und Pegel am D-Sub-Anschluss.

$290 €$

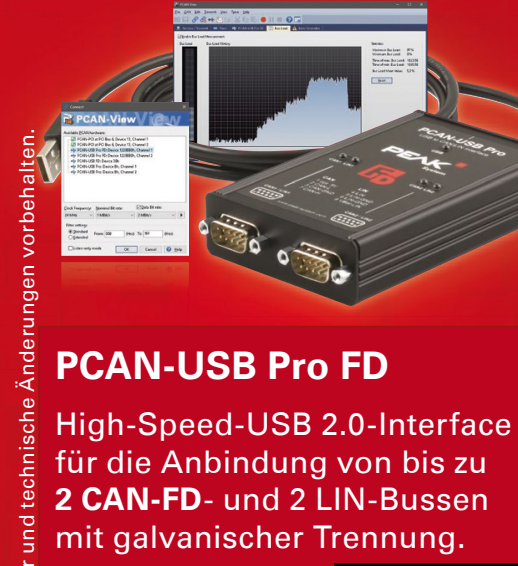

$490 €$

\section{PCAN-Explorer 6}

Professionelle Windows-

Software zur Steuerung und

Überwachung von CAN-FD- und CAN-Bussen.
wwW . peak-system . com

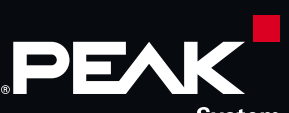

Otto-Röhm-Str. 69 64293 Darmstadt Tel.: $+4961518173-20$ Fax: +496151 8173-29 info@peak-system.com 